\title{
INDISCIPLINA ESCOLAR NO ENSINO FUNDAMENTAL
}

SILVA, Gilveneide Nunes $\mathrm{da}^{1}$

SOARES, Maria de Lourdes de Azevedo²

ANSELMO, Roberto Derivaldo ${ }^{3}$

\section{Resumo}

Apresenta uma investigação qualitativa sobre indisciplina escolar, na perspectiva de um grupo de professores, da quarta série, do Ensino Fundamental, de uma escola da Rede Pública Municipal, situada no município de Taperoá, Estado da Paraíba. Analisa as causas e possíveis mediações acerca da indisciplina no ensino fundamental, visando contribuir para uma melhor prática dos professores no enfrentamento do problema. A metodologia utilizada foi a pesquisa de campo, de caráter qualitativa, com o aporte teórico da pesquisa bibliográfica e coleta de dados junto aos sujeitos objeto do estudo. Entre os resultados obtidos, tem-se a perspectiva apresentada pelos professo res acerca da importância do diálogo com os alunos e da investigação de sua realidade como um possível caminho para descobrir o motivo de sua indisciplina. Concluiu-se que os professores analisados tendem a relacionar a indisciplina mais ao meio familiar ou social ao qual os alunos estão inseridos do que aos possíveis métodos inadequados relacionados à fragilidade das práticas pedagógicas.

Palavras-chave: Indisciplina. Diálogo. Prática Pedagógica.

\section{Abstract}

It presents a qualitative research on school indiscipline, from the perspective of a group of teachers, fourth grade, Elementary School, a school of the Municipal Public Network, located in the municipality of Taperoá, State of Paraíba. It analyzes the causes and possible mediations about the indiscipline in elementary education, aiming to contribute to a better practice of the teachers in facing the problem. The methodology used was the qualitative field research, with the the oretical contribution of the bibliographic research and data collection with the subjects of the study. Among the results obtained are the perspective presented by teachers about the importance of dialogue with students and the investigation of their reality as a possible way to discover the reason for the ir indiscipline. It was concluded that the teachers analyzed tend to relate the indiscipline more to the family or social environment to which the students are inserted than to the possible inadequate methods related to the fragility of pedagogical practices.

Keywords: Indiscipline. Dialogue. Pedagogical Practice.

\footnotetext{
1 Assistente Social. Mestra em Serviço Social pelo Programa de Pós-Graduação em Serviço Social (PPGSS/UFPB). Professora no Curso de Serviço Social da Faculdade Internacional da Paraíba e Secretaria de Estado do Desenvolvimento Humano do Estado da Paraíba.E-mail:neidefelipe@hotmail.com;

2 Licenciada em Pedagogia pel a Universidade Federal da Paraíba.E-mail:Iourdesazevedo@hotmail.com;

3 Advogado e Professor da Universidade Federal da Paraíba. Mestre e Doutor em Educação pela UFPB. Email:robertoanselmo.jus@gmail.com
} 


\section{INTRODUÇÃO}

A indisciplina escolar tem sido objeto de diversas pesquisas, aos quais tentam desvendar os fatores que levam a sua presença cada vez mais frequente nas salas de aula. Tentando compreender esse cenário o presente estudo tem como foco principal a nalisar os fatores como as principais causas da indisciplina, suas influências negativas na aprendizagem, estratégias pedagógicas para lidar com este problema, fatores que estão ligados a esse meio, como também os benefícios trazidos para o processo de ensino quando o aluno é disciplinado.

O trabalho de pesquisa aqui delineado tem natureza e mpírica e busca dados relevantes e convenientes obtidos através da experiência relatada por professores em casos de indisciplina. Observa-se que é grande o desafio que se enfrenta na educação da atualidade quando o assunto é disciplinamento do al uno e consequentemente o seu interesse pela aprendizagem atual e futura. É notório que a indisciplina não interfere só no âmbito escolar, mas na vida pessoal do indivíduo.

Nota-se que indisciplina independe do nível social bem como se a escola é da rede privada ou pública, o que nos leva a questionar o que realmente estão levando essas crianças a serem violentas e indisciplinados. Tenta-se entender o porquê dos professores contemporâneos não conseguirem manter o controle e o equilíbrio de seus alunos; onde em muitas conversas relatou-se que antigamente os alunos não eram tão agressivos como os de hoje, que temiam os professores e se desobedecessem seriam punidos.

Como problemática desta pesquisa analisou-se que os educadores estão vivenciando um tempo de desafios e incertezas e que a indisciplina está cada vez mais presente em sala de aula. Nesse contexto, pergunta-se quais as principais causas dessa indisciplina e o que fazer para combate la? Assim buscou-se as concepções a respeito da indisciplina escolar com aplicação de questionários por meio de uma pesquisa de campo de caráter qualitativo com um grupo de professores, da quarta série, do Ensino Fundamental, de uma escola da Rede Pública Municipal, situada no município de Taperoá no Estado da Paraíba.

\section{O QUE INDISCIPLINA?}

A indisciplina é uma atitude que se relaciona diretamente com os deveres pessoais do individuo que vive em sociedade e que refletem através da falta de ordem, na deliberação e na projeção de metas e que por vezes é responsável pelos fracassos pessoais e profissionais dos inúmeros indivíduos.

Deste modo, compreende-se a indisciplina como uma instabilidade e ruptura no contrato social das relações no processo de ensino aprendizagem. É um elemento no meio e ducacional que contém força para alterar o currículo escolar implementado pelos professores, podendo ocasi on ar a inviabilidade de parte do que havia sido planejado para as aulas. Segundo Garcia (2013, p. 95), a indisciplina também é capaz de induzir mudanças em ideias e práticas educacionais insatisfatórias.

A indisciplina dentro do ambiente escolar vem ocupando um enorme espaço. Isso vem ocorrendo tanto em instituições públicas como privadas, e não só no Brasil, mas também em vários outros países. (OECD, 2009). Certamente este o maior problema enfrentado pela escola brasileira na atualidade, o Brasil chega a se igualar com países africanos como Nigéria e Sudão nos índices de retenção e evasão escolar. Reflexos da indisciplina escolar, a sala de aula torna-se um ambiente indesejado por alunos e até mesmo por professores por não saberem mais o que fazer para solucionar esse problema. 
Um aluno indisciplinado se revolta, não obedece, nem se submete, nem tão pouco se acomoda, provocando dentro da sala de aula um desrespeito e questionamentos, é a incapacidade de se ajustar ás normas e padrões explícitos pela escola, como ci ta Aquino (1996) o ensino teria como um de seus obstáculos centrais a conduta desordenada dos alunos.

Assim, além de está relacionada com os deveres pessoais e que refletem na falta de ordem em termos como: bagunça, tumulto, falta de limites, maus comportamentos, desrespeito ás fi guras de autoridade, as crianças não reconhecem a autoridade dos pais e professores, não querem respeitar e/ou se sujeitar as regras sociais, tornando-se um hábito na vida em sociedade difícil de ser superado, principalmente quando ocorre desde a infância, o que tem gerado inúmeras que ixas por parte da escola que acusam os pais de terem se tornado permissivo demais com seus filhos. Para Vasconcelos (2009, p.240) [...] é muito comum ouvirmos dos professores a queixa de que os pais não estabelecem limites, não educam seus filhos com princípios básicos como saber se comportar respeitar os outros, saber esperar sua vez, etc.

Segundo Vasconcelos (2009, p. 45) as causas da indisciplina podem ser encontradas em cinco grandes níveis: sociedade, família, escola, professor e aluno, que estão profundamente entrelaçados. Todo cidadão nasce em um grupo social, e esse grupo tem interferência em suas escolhas diárias. As mudanças que ocorrem dentro da sociedade afetam os setores psicológicos, racionais e culturais do ser inserido nela, podendo se tornar um indivíduo revoltado, causando a falta de motivação para adquirir os conhecimentos escolares.

São muitos os aspectos que podem influenciar direta e indiretamente o comportamento dos alunos: a forma como os alunos lidam com suas emoções, a realidade escolar, o ambie nte familiar, além do contexto social onde ele está inserido.

O centro de algumas famílias são os filhos, por isso, alguns pais não põe limites, calam-se quando eles falam, acham natural que corram em ambientes fe chados, que se alimentem a qualquer hora, não chamam a atenção quando eles tomam atitudes inadequadas na frente dos outros. Colocar limites nos filhos desde cedo é muito importante e ajuda a disciplinar da maneira correta, muitas famílias não tem consciência dessa tamanha responsabilidade e ficam sem saber o que fazer quan do o filho se torna um aluno-problema.

Quando a família é desestruturada, as pessoas nela inseridas trazem consigo grandes problemas na sociedade e conflitos emocionais que geram distúrbios de aprendizado entre outros que danifica a sua vida em todos os aspectos, podendo ter consequências levadas para toda a vida, cuidar e educar corretamente os filhos e al unos é essencial para o bom disciplinamento.

Por outro lado,os professores/as, se sentem inseguros frente ao desafio da indisciplina na escola e continuam preocupados em como criar um ambiente de aprendizagem escolar mais agradável, em como conseguir a atenção dos alunos e sua respectiva participação nas aulas.

Nesse sentido, a indisciplina não é um fator a ser tratado isoladamente, é perceptível que a gestão escolar e professores busquem por um fazer coletivo na resoluções e desafios desse tema, induzindo o intercâmbio entre família, escola e toda soci edade.

Assim, para alcançar sucesso nessa empreitada, o educador deve apresentar paciência com seus al unos e buscar identificar os pontos principais que merecem atenção, mostrando que a criança terá mais benefícios acatando as regras do que se pondo contra elas. Alunos motivados não exibe m comportamentos indisciplinados. Deste modo, cabe ao professor implementar uma prática educativa que consiga manter todos os alunos interessados no conteúdo ministrado em sala de aula o te mpo 
todo. É um trabalho difícil, uma vez que o processo educativo é coletivo, composto por uma diversidade de sujeitos e culturas, mas possível se alunos e professores se tornarem juntos protagonistas desta mudança. Para Vasconcellos (2009, p. 144).

O professor necessita junto aos difere ntes sujeitos envolvidos no processo educativo, construir um sentido/objetivo nos diversos níveis (estudo, conteúdo, plano de aula), como forma de superar o vazio de sentido existente na pratica pedagógica. O trabalho com projetos didáticos é fundamental neste processo, tendo em vista que "projetar" é apontar para um mundo novo, na confiança de que as coisas podem ser diferentes do que vem sendo, ou seja, o mundo pode ser mudado, e cada aluno/professoré protagonista desta mudança.

Do mesmo modo, aprendemos a ser sujeitos carregados de valores culturais e concepções acerca do mundo que nos cerca. É através da educação que adquire-se conhecimentos científicos que fazem com que o homem possa a cada dia produzir bens, criar novos instrumentos e novas tecnologias e essa formação está diretamente ligada a vários fatores, dentre eles o disci plinamento dos sujeitos envolvidos no processo. Neste sentido, faz-se necessário refletir sobre a temática indisciplina, compreendendo seu significado e os efeitos que ela pod e gerar nas escolas, be m como no processo de ensino-aprendizagem.

A indisciplina é tratada como um comportamento contrário a disciplina, "como um comportamento inadequado, um sinal de rebeldia, intransigência e desacato, traduzi do na fal ta de educação ou de respeito pelas autoridades, na bagunça ou agitação motora" (REGO, 1996, p. 85 apud BASSO, 2010).

Para se alcançar uma disciplina consciente e interativa em sala de aula e na escola o profe ssor deve de forma dialética promover diferentes formas de organização da classe e da escola com os diferentes sujeitos envolvidos no processo educativo, construir um sentido/objetivo nos diversos níveis (estudo, conteúdo, plano de aula), como forma de superar o vazio de sentido existente na pratica pedagógica. 0 grande desafio será o de ressignificar a tradição existente, imprimindo ao processo educativo um caráter emancipador. Segundo Libâneo (2017, p.17),

A educação tem objetivo de [...] prover os indivíduos dos conhecimentos e experiências culturais que os tornam aptos a atuar no meio social e a transformá-lo em função de necessidades econômicas, sociais e políticas da coletividade". Com isso, sob uma ótica social ou individual, o que se infere é que a educação é potencializadora de transformações.

A educação que emancipa e que transforma difere da pedagogia das classes dominantes e requer dos sujeitos envolvidos nesse processo, condições de reflexões, descobertas e conqui stas de suas destinações históricas. Assim, a educação compreende os processos formativos que ocorrem no meio social, nos quais os indivíd uos estão envolvidos de modo necessário e inevitável pe lo simples fato de existirem socialmente.

Todavia, é através da educação que a sociedade exerce controle sobre o sujeito e estes, ao assimilarem e recriarem essas influências, tornam-se capazes de estabelecer uma relação ativa e transformadora em relação ao meio social. Tais influências se manifestam através de conhecimentos, experiências, valores, crenças, modos de agir, técnicas e costumes acumulados por m uitas ge rações de indivíduos e grupos, transmitidos, assimilados e recriados pelas novas gerações. 
Em sentido amplo, a educação compreende os processos formativos que ocorrem no meio social, nos quais os indivíduos estão envolvidos de modo necessário e inevitável pelo simples fato de existirem socialmente; neste sentido, a prática educativa existe numa grande variedade de instituições e atividades sociais decorrentes da organização econômica, política e legal de uma sociedade, da religião, dos costumes, das formas de convivência humana.

O que seria de uma orquestra, se cada músico tocasse o que quisesse? Se não houvesse disciplina? Ela é necessária. E deve ser analisada como um meio e não um fim (VASCONCELLOS, p.27, 2009). Os educadores devem provocar processos de transformação do al uno, conduzindo to da a sala para o disciplinamento, como numa orquestra. Segundo Collarese Moysés, (1996, p. 26).

Pelo discurso dos professores e diretores, a sensação é de que estamos diante de um sistema educacional perfeito, desde que as crianças vivam uma vida artificial, sem nenhum tipo de problemas, enfim, crianças que provavelmente não precisariam da escola para aprender. Para a criança concreta, que vive neste mundo real, os professores parecem considerar muito difícil, senão impossível, ensinar.

Quando disciplinado o aluno volta toda a sua atenção para as explicações do docente e mantem um bom comportamento no ambiente escolar. Muitos pais e professores sabem compartilhar com a criança de modo muito fácil a necessidade de uma regra de forma que a criança até reclama, mas aceita, entendendo que é o melhor.

\section{Os professores frente a indisciplina}

É notório que a sociedade vive em constante evolução. As relações sociais, principalmente quando se considera o desenvolvimento tecnológico e a globalização, passaram por profundas al terações nos último tempos e isso não poderia ter passado imune no ambiente escolar.

Alguém já afirmou que se conseguíssemos, numa suposta máquina do tempo, trazer aos dias de hoje um cirurgião e um professor que viveram há dois séculos, o primeiro ficaria imobilizado e maravilhado com os avanços em sua profissão, pois encontraria um ambiente de trabalho totalmente modificado. O segundo, por sua vez, certamente conseguiria desenvolver sua atividade sem maiores problemas, afinal o ambiente que encontraria seria muito semelhante ao do seu tempo". (KALINKE, 1999, p.16).

Para Kalinke a educação não teve grandes avanços comparados aos sécul os passados, o poder do professor não está mais nos caroços de milhos, palmatórias ou cintos, está simplesmente e m sua presença, que assumiu ao longo do tempo um característico poder dominador, através do convívio diário deles, o aluno saberá o que o professor admite ou repudia, não será necessário o profess or se expressar com palavras, só a sua presença ou um olhar será necessário, nessa perspectiva, a indisciplina dos alunos pode ser sinal de resistência à escola que foi idealizada para um tipo de al uno e está recebendo outro. A autonomia do professor é fator necessário frente a indisciplina.

Deste modo, para a superação da indisciplina a meta a ser seguida pelo professor nas relações pedagógicas passa a ser a do desenvolvimento da autonomia do docente. Para tanto, a in disciplina precisa ser entendida como resultante do processo de socialização/descentração que leva o al uno a sair de seu egocentrismo, característico dos estados de heteronomia, para cooperar e submeter-se conscientemente às regras. Assim, para La-Taille, (2010, p. 14-15): "não se trata de fazer belos discursos sobre o bem e o mal, mas o de organizar o convívio escolar de forma que esse seja a 
expressão da justiça e dignidade com regras, sim, mas construídas, partilhadas e avaliadas com a participação de todos."

Toda vez que se tenta impor a disciplina com autoritarismo, surge a revolta. Assim, o segre do está em trazer o aluno para perto do professor, com a finalidade de criar vínculos de afeto, de compreensão dos seus problemas e apoia-lo, o que se faz necessário diversificar as metodologias, pois interagimos com alunos conectados ao mundo de diferentes maneiras, pois cada criança tem uma realidade diferente, sendo plausível que o professor alcance as carências de seus alunos.

\section{A função social da escola básica}

Antes de tudo é preciso entender que a escola precisa ser mais que um lugar que transmite conteúdos engessados e espera que os alunos saiam por aí reproduzindo-os. A escola deve desenvolver o aluno para o convívio social e a vida profissional, torna-lo um cidadão de direitos e deveres, crítico e de ideias próprias, com autonomia para alcançar suas metas. E para isso, é pre ciso diálogo, discussões, projetos, e não apenas por quadros-negros, avaliações e livros.

Ter autonomia é obter a capacidade de governar-se pelos próprios meios, para o profess or é de grande importância que aluno tenha autonomia para formar e expressar suas opiniões sobre assuntos abordados na sala e no cotidiano social, a escola deve incentivar essa autonomia, através desse incentivo ajudar a forma um indivíduo de opiniões próprias e críticas. Segundo Barroso (1996, p. 17) a autonomia é uma maneira de gerir, orientar, as diversas dependências em que os indivíduo s e os grupos se encontram no seu meio biológico ou social, de acordo com as suas próprias leis.

Neste contexto, entende-se que a escola tem a função social de dar autonomia ao aluno possibilitando o autogoverno, repensando suas atitudes na escola, na família, na sociedade, se fazendo uma autocrítica reconhecendo as qualidades e os defeitos do próprio caráter, ou os e rros e acertos de suas ações, contribuindo assim para sua melhoria enquanto aluno, filho e cidadão, incentivar gerações para serem seres humanos cada vez melhores é um papel importante da escola, seus alunos que poderão modificar o futuro para algo melhor.

\section{A PESQUISA DESENVOLVIDA}

É importante esclarecer que a indisciplina, tema desta pesquisa, representa um problema real e marcante no contexto da unidade escolar pesquisada. Deste modo, este trabal ho te $\mathrm{m}$ como base uma pesquisa de campo de caráter qualitativo, a qual procura compreender diferentes comportamentos através de opiniões e relatos feitos por pessoas que conviveram com o tema estudado visando a construção da realidade.

Os dados coletados são relacionados a luz dos teóricos estuda dos sobre o tema, apresentando o nível de concordância e discordância entre as respostas dos entrevistados e as ideias dos autores estudados. Godoy (1995, p. 58) descreve características de uma pesquisa qualitativa e considera,

[...] o ambiente como fonte direta dos dados e o pesquisador como instrumento chave; possui caráter descritivo; o processo é o foco principal de abordagem e não o resultado ou o produto; a análise dos dados foi realizada de forma intuitiva e indutivamente pelo pesquisador; não requereu o uso de técnicas e métodos estatísticos; e, por fim, teve como preocupação maior a interpretação de fenômenos e a atribuição de resultados. 
Com a pesquisa qualitativa, os entrevistados estão mais livres para apontar os seus pontos de vista sobre determinados assuntos que estejam relacionados com o objetivo de estudo, normal mente essa pesquisa é feita com um número baixo de entrevistados com respostas obje tivas e propósito de compreender determinados comportamentos de um grupo-alvo. Sobre o assunto Richardson (1999, p. 102) afirma que:

[...] o objetivo fundamental da pesquisa qualitativa não reside na prod ução de opiniões representativas e objetivamente mensuráveis de um grupo; está no aprofundamento da compreensão de um fenômeno social por meio de entrevistas em profundidade e análises qualitativas da consciência articulada dos atores envolvidos no fenômeno.

Compreende-se que a validade da pesquisa não se dá pelo tamanho da amostra, como na pesquisa quantitativa, mas, sim, pela profundidade com que o estud o é realizado. Seguindo a mesma linha de raciocínio, Trivinõs (2008) esclarece que na pesquisa qualitativa tem diversos recursos e podem ser usados para anexar a amostra. Sendo assim, pode-se decidir intencionalmente o tamanho da amostra, considerando uma série de condições, como sujeitos que sejam essenciais para o esclarecimento do assunto em foco, segundo o ponto de vista do investigador, facilidade para se encontrar com as pessoas, tempo dos indivíduos para a entrevista e assim por diante. Está Pesquisa está desenvolvida também através de leituras bibliográficas.

\section{Caracterização da escola e dos participantes da pesquisa}

A pesquisa foi desenvolvida no município de Taperoá no Estado da Paraíba em uma escola municipal ao qual foram aplicados questionários com 3 (três) professores do 4o (quarto) ano do ensino fundamental. As salas de aula dos professores eram compostas por uma média de 20 a 23 alunos porsala.

A escolha das professoras foi feita através da disponibilidade experiências vividas por c ada uma e por acreditar que no quarto ano do ensino fundamental ocorre o maior número de conflitos e casos de indisciplina por ser uma faixa etária de pré-adolescência.

A escolha pela escola objeto do estudo se deu pelo fato de ser uma das maiores escolas do município e ter como beneficiário o público de baixa renda, que na maioria das vezes não tem direito a voz ou não sabem se utilizar dela. É importante esclarecer que a indisciplina, tema desta pesquisa, representa um problema real e marcante no contexto da unidade escolar, o que levou a pesquisadora, a tentar uma intervenção junto aos outros professores.

O instrumento de pesquisa utilizado foi uma aplicação do questionário realizada através de uma visita as escolas com cinco questões abertas e fechadas. A elaboração do questionário teve como base algumas pesquisas anteriores sobre a indisciplina escolar, bem como os estudos de teóricos, aos quais utilizaram questionários como instrumento de coleta de dados, tentando assim se aproximar ao máximo da realidade atual. O questionário, segundo Gil (1999, p. 128), pode ser definido:

como a técnica de investigação composta por um número mais ou menos elevado de questões apresentadas por escrito às pessoas, tendo por objetivo o conhecimento de opiniões, crenças, sentimentos, interesses, expectativas, situações vivenciadas etc. 
Não existe uma metodologia padrão para o projeto de questionários, porém existem recomendações de diversos autores com relação a essa importante tarefa no processo de pesqui sa científica. (Marconi \& Lakatos, (1999, 100), afirma em suas ideias que o questionário é um Instrumento de coleta de dados constituído por uma série de perguntas, que de vem ser respondidas por escrito. Com isso se constituem algumas vantagens como: Economia de tempo, atinge um maior número de pessoas, obtém respostas mais exatas, os entrevistados têm liberd ade de resposta e mais tempo para responder.

\section{Analise e discussão dos dados}

Através das respostas dos professores entrevistados foi possivel detectar algun s mo tivos que incentivam a indisciplina. Alguns educadores delegam a culpa a base familiar, outros ao meio social onde a criança está inserida, ou até mesmo ao método ao qual o professor utiliza para transmitir o conhecimento em sala de aula assim como sua postura mediante ao cumprimento de regras.

Constata-se que a indisciplina é um problema recorrente no ambiente escolar, encarado por professores e pais diariamente, tanto em escolas públicas como também em particulares, a agressividade pode estar presente desde o público infantil ao adolescente e até mesmo adulto, dentro e fora da sala de aula. O convívio e criação familiar é sem dúvida a causa mais apontada entre os entrevistados como a causa chave para a indisciplina, uma vez que falta limites a criança por partes dos pais.

Relativamente à questão de estudo número um (Q1: sobre as dificuldades encontradas no âmbito escolar), os professores responderam:

"A falta de acompanhamento dos pais dificulta muito no âmbito escolar" (prof. 1)

"A indisciplina, a falta de acompanhamento da família com a aprendizagem dificulta muito no âmbito escolar" (prof. 2)

"A falta de apoio familiar, e de variedade de material pedagógico dificulta" (prof. 3)

Os professores/as apresentam a compreensão de que a falta de acompanhamento familiar realmente ainda é muito presente no âmbito escolar, sendo essencial uma parceria entre pais e escola para um bom desempenho escolar dos alunos. Segundo Tiba (1996), a educação ativa formal é dada pela escola, mas necessita de acompanhamento fora do âmbito escolar. Ambos os ambientes devem estar em consonância para que a disciplina seja posta em prática.

Por conseguinte, é necessário aos pais impor limites aos filhos desde criança em seu lar, para que a criança possa reconhecer seus pais. como figuras de autoridade e posteriormente seus professores, se isso não acontecer trará muitas consequências negativas dentro da escola. A família logicamente é uma das peças chaves para o disciplinamento da criança, deve-se buscar o equil íbrio entre liberdade e responsabilidade por parte da família e escola, conforme vimos nas palavras de Tiba, escola e familiar devem caminhar juntos até mesmo porque segue a lógica: crianças indisciplinadas em casa, alunos indisciplinados na escola.

$\mathrm{Na}$ análise dos resultados relativos à questão de estudo número dois (Q2: Quando perguntados sobre o conceito de indisciplina), os professores responderam: 
"Se caracteriza pela desobediência, falta de limites, comportamento inadequado diante de pessoas, lugares e situações" (Prof. 1)

“Falta de apoio familiar' (Prof. 2)

"Falta de limites em casa e na escola" (Prof. 3)

A indisciplina está ligada fortemente a falta de limites, uma criança precisa ser conduzida pelos seus responsáveis, Ihe orientando sobre como agir. Segundo De La Taille (1994), se desde cedo a criança aprende que há limites a serem respeitados, aos poucos ela própria vai compreendendo que as regras são como contratos estipulados para que todas as partes sejam beneficiadas.

Para os entrevistados a falta de limites está totalmente ligada a indisciplina, De La Taille traduz nesse pensamento que a criança deve saber desde ce do que existe liberdade e re sponsabilidades, que se desde cedo é ensinado isso ela levará essas ideias para o resto da vida. É importante que o educador conheça o cotidiano do aluno, para assim observar o motivo de sua indisciplina, para assim entendê-lo e ajudá-lo da forma correta.

$\mathrm{Na}$ análise dos resultados relativos à questão de estudo número três (Q3: Quando perguntados sobre comunicação entre pais e professores sobre identificação de problemas indisciplinares), os professores responderam:

"Sim, só é possível solucionar o problema, através do acompanhamento dos pais" (Prof. 1)

"Sim, porque o processo de ensino aprendizagem envolve a parceria da familia e escola" (Prof. 2)

"Sim, A família deve estar ciente do que acontece na escola" (Prof. 3)

Os pais até mesmo os desinteressados sobre a vida escolar dos filhos, devem ser procurados e informados sobre o comportamento do seu filho na escola, os educadores devem conscientizar esses pais da importância do acompanhamento da vida escolar da criança. Tiba (2005) considera que se a parceria entre família e escola for formada desde os primeiros passos da criança, todos terão muito a lucrar. A criança, que estiver bem vai melhorar e aquela que tiver problemas receberá a ajuda tanto da escola quanto dos pais para superá-los.

Uma base familiar bem construída é essencial para a formação de um indivíduo com princípios bem definidos, como Tiba afirma em suas palavras a parceria de escola e família é fundamental e o diálogo diário mesmo que a criança vá bem ou mal, esse contato sempre deve existir. Com esse contato todos vão lucrar, a escolar por ter um aluno dedicado e disciplinado, a família por ter um filho educado na escola e em casa.

Com relação à questão de estudo número quatro (Q4: Quando perguntados sobre quais estratégias os professores podem utilizar em situações de indisciplina), os educadores responderam:

"Conquistá-lo aos poucos, dar-Ihe responsabilidades na sala de aula que Ihe motive" (Prof. 1)

"Trazer jogos, fazer dinâmicas relacionadas ao assunto apresentado, usar de jogos didáticos para chamar atenção dos alunos." (Prof. 2) 
"Tentar descobrir o motivo ao qualo aluno está agressivo, busca ser a migo e compreende-lo" (Prof. 3)

A aproximação com a criança pode ser uma solução para motiva-la a ir à escola e se comportar, uma aula diferente com novidades cativa e ganha o interesse a aprendizagem na criança. Para (WERNECK, 2005, p. 63-64):

[...] Nesses casos torna-se necessário que a escola use seus meios de educação, tais como: orientação educacional, psicólogo, entrevista com setores encarregados da convivência escolar, chamada dos pais à escola para entrevista, usando os tempos destinados às aulas para que se proce da à reeducação. Essa questão, porém, continuará a ser uma tarefa da escola e da família. Quando faz pirraça, uma criança pode ser engraçada; quando, todavia, a partir de quatro anos começa a chutar pessoas, convém perguntar: quem precisa de tratamento, a criança ou a família dela? 0 mesmo ocorre em relação à sala de aula: quem precisa mudar, o aluno ou o professor?

Em suas palavras Werneck deixa uma reflexão aos pais e professores, sobre quem deve mudar de fato, essa reflexão é válida, se os pais ou professores acham engraçados as pirraças da criança ele está sendo conivente para que o mesmo perpetue assim, quando enxergam o erro que vão querer corrigi-lo o problema já estará muito maior.

Para os professores entrevistados a tentativa de aproximação é um caminho a tentar-se, algumas crianças não recebem a devida atenção em casa e tentam a todo custo chamar a atenção do professor, mas nem sempre isso fica nítido ao educador, em alguns casos podem ser necessária a ajuda de terceiros, como gestão escolar, psicopedagogo e outros órgãos se assim se assim se fizer viável como o concelho tutelar local.

Analisando as respostas dadas a questão cinco (Q5: Quando perguntados sobre fatores que podem ser a causa da indisciplina), os professores responderam:

"Acredito que a causa está ligada a parte social familiar, pois na maioria das vezes o problema parte de alguns acontecimentos em casa" (Prof. 1)

"Para se afirmar é preciso investigar para poder falar com propriedade, porém com base nas experiencias vividas em sala de aula, observa-se que está relacionada com mais ênfase ao fatorfamiliar" (Prof. 2)

"Pode estar ligado tanto ao fator familiar quanto ao social, são diversos casos. (Prof.3)

Muitas vezes a falta de atenção e de limite a criança por parte da família acarreta diversos problemas e o mais grave é a indisciplina. Para Vasconcellos (2009, p. 55), a indisciplina é um processo que agrega muitos fatores: o desinteresse do al uno proveniente, por exemplo, da influência midiática externa ao ambiente escolar geralmente mais atrativa que a escola; a família que não cumpre com o papel de educar para os limites; a escola que não apoia o professor pedagogicamente e a influência da desorganização da sociedade.

Em alguns casos é necessário a mudança também do professor e da família, para isso é necessário uma autoavaliação, as causas da indisciplina pode ser a metodologia do professor, a 
tratamento recebido em casa, a falta de limites, fatores sociais, enfim, são muitas as causas possíveis a serem investigadas. Uma criança indisciplinada pode ainda tornar outras iguais a elas, influenciando negativamente seus colegas de turma, complicando ainda mais o controle de sala pelo professor.

A indisciplina em sala de aula acontece quando começa a atrapalhar o desempenho individual e coletivo dos alunos, cabe ao professor ver quem é o causador de tais dificuldades e buscar soluções, em parceria com a família e a gestão escolar. Assim o educador através de orientações e parcerias facilitará a resolução do problema e aprendizagem do aluno.

\section{CONSIDERAÇÕES FINAIS}

A pesquisa possibilitou compreender que a indisciplina está ligada, sobremodo a falta de limites e as regras dadas pelos pais em casa. Os atos indisciplinares ocorridos em seus lares refle te $m$ diretamente na sala de aula e na escola, através de dificuldades em cumprir regras, agressividade com colegas e professor, além da dificuldade de aprendizagem.

Alguns professores expressam dificuldades para encontrar soluções de combate a indisciplina . Conforme as análises dessa pesquisa foram possíveis detectar que os métodos utilizados pela maioria dos professores são adquiridos com suas experiências, outros pesquisam novidades meios de to rnar suas aulas mais atrativas para o alunado.

Saliente-se, contudo, a importância do professor não se isentar do problema, responsabilizando apenas a família. Não se pode negar que a família tem grande responsabilidade sobre o filho, porém, no ambiente escolar o professor é o responsável por a atitudes de seus al unos, especialmente dentro da sala de aula. Todos os problemas devem ser solucionados entre escola e família, só assim se obterá êxito.

O diálogo deve sempre está presente entre escola, família e aluno, buscando soluções viáveis para melhorar a aprendizagem e comportamento do aprendente. Os educadores entendem que tirar notas ou suspender pode causar mais transtornos, e não irá resolver a situação, é necess ário fazer o aluno refletir sua conduta, compreendendo que certas atitudes e agressões podem causar vários danos. Os alunos devem ser instigados a descobrir, a associar, a discernir, a pensar, despertar a curiosidade, a participação, o desejo e o gosto pelo saber, despertar neles a compreensão de que direitos e deveres são coisas que caminham lado a lado. Esse é o um bom caminho para a disciplina.

\section{REFERÊNCIAS}

AQUINO, Julio Groppa. Indisciplina na Escola: Alternativas Teóricas e Práticas. São Paulo: Summus. 1996.

BASSO, Cláudia de BASSO, Cláudia de Fatima Ribeiro. Indisciplina escolar. Blumenau: IADE, 2010.

COLLARES, Cecília A. L.; MOYSÉS, Maria Aparecida. Preconceitos no cotidiano escolar: ensino e medicalização. São Paulo: Cortez, 1996.

DE LA TAILLE, Yes. Prefácio à edição brasileira. 1994. In: Piaget, Jean. O juízo moral na criança. São Paulo: Ática, 1998

KALINKE, Marco Aurélio. Para não ser um professor do século passado. Curitiba: Editora Gráfica Expoente, 1999. 
BARROSO, J. 0 reforço da autonomia das escolas e a flexibilização da gestão escolar em Portugal . In : FERREIRA, N. S. C. (org.) Gestão Democrática da educação: atuais tendências, novos desafios. São Paulo: Cortes, 1998.

GARCIA, J. A indisciplina e seus impactos no currículo escolar. Nova Escola. São Paulo, ed. 261, abril, 2013.

GIL, Antônio Carlos. Métodos e técnicas de pesquisa social. 5. ed. São Paulo: Atlas, 1999.

GODOY, A.S. Introdução à pesquisa qualitativa e suas possibilidades. In: Revista de Administração de Empresas. São Paulo:v.35, n.2, p. 57-63, abril 1995.

LIBÂNEO, José Carlos. Didática. Cortez Editora, 2017.

MARCONI. M. A.; LAKATOS, E. M. Técnicas de pesquisa. São Paulo: Atlas, 1999.

RICHARDSON, R. J. Pesquisa social: métodos e técnicas. São Paulo: Atlas, 1999.

TRIVIÑOS, A. N. da S. Introdução à pesquisa em ciências sociais: a pesquisa qualitativa em educação. São Paulo: Atlas, 2008.

TIBA, Sçami. Disciplina, limites na medida certa. São Paulo: Editora gente; 1ํ Ed, 1996.

WERNECK, Hamilton. Pulso forte e coração que ama: A indisciplina tem jeito. Ed. DP\&A. Rio de Janeiro. 2005

DOS SANTOS VASCONCELLOS, Celso. Indisciplina e disciplina escolar: fundamentos para o trabalho docente. Cortez Editora, 2009.

Os desafios da indisciplina em sala de aula e na escola. Disponível em: <http://www.sinterroraima.com.br/imagens/artigos/desafiosindisciplinas01pag.>. Acesso em 03/01/2019. 